\title{
Characterization of a novel adult murine immortalized microglial cell line and its activation by amyloid-beta
}

Ryan C. McCarthy ${ }^{1}$, Dah-Yuu Lu,2, Ahmed Alkhateeb ${ }^{1,3}$, Andrew M. Gardeck', Chih-Hao Lee ${ }^{1}$ and Marianne Wessling-Resnick ${ }^{1^{*}}$

\begin{abstract}
Background: Alzheimer's disease is associated with amyloid-beta (A $\beta$ )-induced microglia activation. This pro-inflammatory response promotes neuronal damage, and therapies are sought to limit microglial activation. Screening efforts to develop new pharmacological inhibitors require a robust in vitro cell system. Current models lack significant responses to $A \beta$, and their use in examining age-related neurodegenerative diseases is questionable. For example, the commonly used BV-2 microglial line was derived from embryonic mononuclear cells and its activation by various stimuli is limited. To this end, we have established a new immortalized microglial (IMG) cell line from adult murine brain. The objective of this study was to characterize A $\beta$-induced activation of IMG cells, and here, we demonstrate the ability of cannabinoids to significantly reduce this inflammatory response.

Methods: Microglial cells derived from adult murine brain were immortalized via infection with the v-raf/v-myc retrovirus under conditions that selectively promote microglia growth. The presence or absence of markers CD11b and F4/80 (microglial), NeuN (neuronal), and GFAP (astrocytic) was assessed by immunofluorescence microscopy and western blotting. Using IMG and BV-2 cells, levels of pro- and anti-inflammatory transcripts in response to extracellular stimuli were determined by quantitative PCR (qPCR). Phagocytosis of fluorescent beads and fluorescein isothiocyanate (FITC)-labeled A $\beta$ oligomers was assessed using flow cytometry and fluorescence microscopy. FITC-A 3 uptake was quantified using a fluorescence plate reader. The ability of cannabinoids to mitigate $A \beta$-induced expression of inducible nitric oxide synthase (iNOS) was evaluated.
\end{abstract}

Results: IMG cells express the microglial markers CD11b and F4/80 but not NeuN or GFAP. Relative to BV-2 cells, IMG cells increased iNOS (>200-fold) and Arg-1 (>100-fold) in response to pro- and anti-inflammatory stimuli. IMG cells phagocytose foreign particles and A oligomers, with the latter trafficked to phagolysosomes. A $\beta$-induced activation of IMG cells was suppressed by delta-9-tetrahydrocannabinol and the CB2-selective agonist JWH-015 in a time- and concentration-dependent manner.

Conclusions: IMG cells recapitulate key features of microglial cell activation. As an example of their potential pharmacological use, cannabinoids were shown to reduce activation of A cells hold promising potential for drug screening, mechanistic studies, and functional investigations directed towards understanding how $A \beta$ interacts with microglia.

Keywords: BV-2 cells, Neurodegeneration, Microglia, Neuroinflammation, IMG cells, Amyloid-beta

\footnotetext{
* Correspondence: wessling@hsph.harvard.edu

'Department of Genetics and Complex Diseases, Harvard School of Public

Health, 655 Huntington Avenue, Boston, MA 02115, USA

Full list of author information is available at the end of the article
} 


\section{Background}

Microglial cells, often thought of as the resident macrophages of the central nervous system (CNS), act as the immune cells of the brain and spinal cord. Microglia become activated by disturbances in the homeostasis of their local microenvironment. Activation of microglial cells results in a cascade of phenotypic changes including, but not limited to, morphology, transcription, and cytokine production. While there are varying degrees of microglia activation [1], two main polarized states are established: a pro-inflammatory reactive state induced by exposure to stimuli like lipopolysaccharide (LPS) and interferon- $\gamma$ (IFN $\gamma$ ) and an anti-inflammatory state to promote repair and resolution of inflammation, which is induced by factors such as interleukin-4 (IL-4) and interleukin-13 (IL-13) [2, 3].

The ability to polarize between reactive and repair states allows microglia to actively transition from an immune-stimulating antimicrobial phenotype to one that supports tissue repair and resolution of inflammation [1]. Dysregulation of the activation state of microglial cells can be detrimental to CNS health. Several neurodegenerative diseases including Alzheimer's disease and Parkinson's disease have been attributed to chronically activated pro-inflammatory microglial cells [4-10]. Chronic activation of microglial cells is thought to result from multiple stimuli ranging from systemic infection, misfolded proteins, or cellular debris within the CNS [5]. In the case of the Alzheimer's disease brain, microglia are activated by amyloid- $\beta(A \beta)$ peptides, which are cleared from the interstitium by phagocytosis. As the disease persists, microglia become chronically activated by $A \beta$ peptides and produce excessive amounts of proinflammatory cytokines leading to autocrine reduction of microglial $A \beta$ receptors and ultimately decreased $A \beta$ clearance from the interstitium [11].

Regardless of the provoking stimuli, efforts to target activated microglia for the treatment of certain neurodegenerative diseases include pharmacological repolarization to the more anti-inflammatory phenotype $[2,12]$; cannabinoids represent one class of pharmacological agents currently being examined. Unfortunately, studies of microglial cell function are limited by low yields of primary microglial cells (approx. 500,000 cells per adult mouse brain) along with potential activation during isolation. Several immortalized microglia cell lines have been generated $[13,14]$ and provide experimental advantages of a homogeneous population of cells that can proliferate more rapidly. Most microglial cell studies have relied on the murine BV-2 cell line which was immortalized by infection of embryonic brain mononuclear cells with a v-raf/v-myc oncogene-carrying retrovirus $[14,15]$. However, more recent evidence suggests that microglial cells of the adult brain are derived from myeloid progenitors [16]. Therefore, the embryonic origin of BV-2 cells raises questions about their epigenetic state and whether they truly resemble resident microglia in the adult brain.

Here, we report the generation and characterization of a novel cell line using microglia purified from the adult mouse brain. These cells were established using the Percoll gradient isolation followed by culture conditions that selectively promote microglial cell growth $[17,18]$. This study characterizes the properties of the immortalized microglia (IMG cells), which express markers specific to primary adult microglial cells (CD11b and F4/ 80). IMG cells respond to pro-inflammatory (LPS and $A \beta$ ) or anti-inflammatory (IL-4) stimuli. The changes induced by LPS, $A \beta$, and IL- 4 are far greater than those induced in BV-2 cells. IMG cells provide a model system for drug candidate screening as evidenced by inhibition of $\mathrm{A} \beta$-induced $\mathrm{M} 1$ activation by the cannabinoids delta9-tetrahydrocannabinol (THC) and JWH-015. Lastly, we demonstrate that IMG cells retain the ability to engulf fluorescent beads and fluorescein isothiocyanate (FITC)-labeled $A \beta$ by phagocytosis, functions that are important to explore experimentally to further our understanding of complex $A \beta$-microglia interactions in Alzheimer's disease.

\section{Methods}

\section{Cell culture and reagents}

IMG, C6 glioma, and BV-2 cells were cultured in Dulbecco's modified Eagle medium (DMEM) with high glucose $(4.5 \mathrm{~g} / \mathrm{L}), 10 \%$ fetal bovine serum (FBS) and penicillin/streptomycin $(100 \mathrm{U} / \mathrm{mL})$. SH-SY5Y cells were maintained in DMEM/F12 (1:1 ratio) media with $10 \%$ FBS and penicillin/streptomycin $(100 \mathrm{U} / \mathrm{mL})$. IFNy, IL$1 \beta$, TNF- $\alpha$, IL-4, IL-6, and IL-13 were purchased from Peprotech (Rocky Hill, NJ). LPS, Ac-YVAD-CMK, delta9-tetrahydrocannabinol, and JWH-015 were purchased from Sigma Aldrich. Adenosine triphosphate (ATP) was purchased from Amersham Biosciences.

\section{Primary microglia isolation and generation of IMG cell line}

Microglia were purified from adult brain using gradient isolation methods [19]. Proliferation and retroviral infection was carried out in medium conditioned with growth factors GM-CSF and M-CSF to selectively support microglial growth. Briefly, 8-week-old C57BL/6J mice were perfused with ice-cold phosphate-buffered saline (PBS) through the left ventricle. After collagenase digestion of brain slices, and debris removal, microglia were isolated on Percoll gradients (30\%-37 \%-70\%) and collected at the 37-70\% interface. Microglial cells were maintained in DMEM (5 mM glucose), $10 \% \mathrm{FBS}$, and $1 \% \mathrm{P} / \mathrm{S}$ using $30 \% \mathrm{~L} 929$ cell-conditioned medium to 
induce proliferation of microglial cells. Cells proliferated at days 5-10 after plating. To immortalize the cells, they were re-plated and infected with $\mathrm{v}$-raf/v-myc retrovirus (J2-conditioned medium [20]), supplemented with $30 \%$ L929-conditioned media and $4 \mu \mathrm{g} / \mathrm{mL}$ polybrene. The next day, the medium was replaced by DMEM $(4.5 \mathrm{~g} / \mathrm{L}$ glucose), $10 \% \mathrm{FBS}$, and $1 \% \mathrm{P} / \mathrm{S}$.

\section{Flow cytometry}

IMG cells were grown on a $10-\mathrm{cm}$ tissue culture dish until $80 \%$ confluent. After addition of $5 \mathrm{~mL}$ fresh media, cells were lifted off the dish using a cell scraper. IMG cells were resuspended to $1 \times 10^{8}$ cells $/ \mathrm{mL}$ and incubated with fluorescently conjugated CD11b (Alexa 647 conjugate; Serotec), F4/80 (allophycocyanin (APC) conjugate; Caltag), or appropriate isotype control (BioLegend) antibodies (1:10 dilution) in the dark for $15 \mathrm{~min}$ at $4{ }^{\circ} \mathrm{C}$. Cells were then washed three times with $2 \mathrm{~mL}$ cellstaining buffer (BioLegend). After washing, cells were resuspended in cell-staining buffer and were analyzed by flow cytometry (FACSCalibur, BD Biosciences). Acquired data were analyzed using FlowJo data analysis software (FlowJo, LLC).

\section{Fluorescence microscopy}

IMG and SH-SY5Y cells grown on poly-D-lysine-coated coverslips were fixed for $20 \mathrm{~min}$ with $4 \%$ formaldehyde at $4{ }^{\circ} \mathrm{C}$ in PBS containing $0.5 \mathrm{mM} \mathrm{MgCl} 2$ and $1 \mathrm{mM}$ $\mathrm{CaCl}_{2}\left(\mathrm{PBS}^{++}\right)$. Cells were then permeabilized with $0.5 \%$ Triton-X100 in $\mathrm{PBS}^{++}$for $5 \mathrm{~min}$ at room temperature. After blocking with $1 \%$ bovine serum albumin (BSA) and $0.3 \mathrm{M}$ glycine in $\mathrm{PBS}^{++}$for $1 \mathrm{~h}$ at room temperature, cells were incubated for $1 \mathrm{~h}$ at room temperature with anti-NeuN (Millipore, MAB377) (1:100), anti-F4/80 (Caltag, MF48020) (1:100), or anti-CD11b (Serotec) (1:100). Cells were then washed and incubated for $1 \mathrm{~h}$ at room temperature with Alexa Fluor 568-conjugated anti-rabbit or anti-mouse antibody (1:1000, Invitrogen) in $1 \% \mathrm{BSA}$ in $\mathrm{PBS}^{++}$. Coverslips were mounted onto glass slides using DakoCytomation fluorescent mounting medium (Carpinteria, CA). Images were obtained using a Zeiss AxioImager Z1 Axiophot wide-field fluorescence microscope and were analyzed by Zeiss AxioVision software (Zeiss, Thornwood, NY).

\section{Immunoblot}

IMG and C6 glioma cells were incubated for $24 \mathrm{~h}$ in full growth medium plus $100 \mathrm{ng} / \mathrm{mL}$ IL-6 to allow for astrocytic differentiation of $\mathrm{C} 6$ glioma cells [21]. For cytosolic protein extracts, cells were lysed in hypotonic buffer using $1 \%$ NP-40 plus protease inhibitors (Calbiochem Cat. No. 539134; 1:100 dilution) on ice followed by centrifugation to separate the remaining nuclei (pellet) from the cytosolic fraction (supernatant). The nuclei- containing pellets were lysed with RIPA buffer plus protease inhibitors for $30 \mathrm{~min}$ on ice. Protein concentration was determined, and $30-50 \mu \mathrm{g}$ of protein/sample was heated for $5 \mathrm{~min}$ at $95{ }^{\circ} \mathrm{C}$, cooled on ice, and then resolved on a 4-15\% SDS-PAGE gel (10\% SDS-PAGE gel used for cytosolic and nuclear extracts). The protein was transferred onto a nitrocellulose membrane $(0.2 \mu \mathrm{m})$ using a Trans-blot turbo transfer system (Bio-Rad, Hercules, CA). The resulting membrane was blocked for $1 \mathrm{~h}$ at room temperature in TBST (Tris-buffered saline plus $0.05 \%$ Tween-20) plus $5 \%$ milk. After three washes with TBST, the membrane was incubated with primary mouse monoclonal GFAP (GA5) antibody (1:1000 dilution; Cell Signaling Technology, Beverly, MA), rabbit monoclonal NeuN antibody (1:1000 dilution; Abcam Inc., Cambridge, MA), rat monoclonal F4/80 antibody (1:10,000 dilution; AbD Serotec), rabbit polyclonal $\beta$ tubulin antibody (1:500; Abcam), or rabbit monoclonal Lamin B1 antibody (1:10,000 dilution; Abcam) in TBST plus $5 \%$ milk overnight at $4{ }^{\circ} \mathrm{C}$. The membrane was washed three times with TBST and then was incubated for $1 \mathrm{~h}$ at room temperature with IRDye $800 \mathrm{CW}$ donkey anti-mouse or anti-rabbit IgG (1:5000 dilution; Li-Cor, Lincoln, NE) in TBST $5 \%$ milk (anti-rat HRP 1:5000 dilution was used to probe for F4/80 primary antibody). The membrane was washed three times with TBST and was imaged using Li-Cor Odyssey 2.1 infrared detection technology.

\section{Quantitative RT-PCR}

Total RNA was extracted from IMG or BV-2 cells using TRIzol reagent (Invitrogen, Carlsbad, CA) as per the manufacturer's instructions. For analysis of adult microglial markers, microglia were pre-incubated for 5 days in full growth medium plus mouse recombinant carrierfree MCSF (10 ng/mL; R\&D Systems) and recombinant TGF $\beta 1$ (50 ng/mL; Miltenyi Biotec) as described [26]. RNA was purified and on-column DNAse treated using the Direct-zol RNA Miniprep Kit from Zymo-research (Irvine, CA) as per the manufacturer's instructions. Purified RNA was then reverse-transcribed using the SuperScript $^{\circ}$ III First-Strand Synthesis System (Invitrogen) along with oligo(dT)20 primers and random hexamers. Quantitative PCR was performed using iTaq Universal SYBR green Supermix (Bio-Rad, Hercules, CA) and the StepOnePlus Real-Time PCR System (Life Technologies, Grand Island, NY). In all cases, 36B4 was used as an internal control. Primers used for quantitative PCR (qPCR) are listed in Table 1.

\section{Enzyme-linked immunosorbent assays}

Mini enzyme-linked immunosorbent assay (ELISA) development kits (Peprotech, Rocky Hill, NJ) were used to detect murine TNF- $\alpha$, IL- 6 , and IL- $1 \beta$ expression by IMG 
Table 1 Primer list used for qPCR

\begin{tabular}{lll}
\hline Transcript & Forward primer & Reverse primer \\
\hline Mouse $36 \mathrm{~B} 4$ & AGATGCAGCAGATCCGCAT & GTTCTTGCCATCAGCACC \\
Mouse iNOS & GTTCTCAGCCCAACAATACAAGA & GTGGACGGGTCGATGTCAC \\
Mouse TNF-a & AAATGGCCTCCCTCTCATCAG & GTCACTCGAATTTGAGAAGATGATC \\
Mouse IL-1 $\beta$ & AGCTTCAGGCAGGCAGTATC & AAGGTCCACGGGAAAGACAC \\
Mouse Mgl1 & CACAGTCTGGCAGTTGGAAG & GGGAGTGTGATGTCAGTGTG \\
Mouse Ym1 & GCGAGGCTACAATGATATACGAAAACCTCC & GCGCTCAGACGAGAGCTCCTAGCTCTCC \\
Mouse Itgb5 & AGAAGGGAGTTCAAACCTGGT & GTCTTGCTCATGTGTGTAAGTGA \\
Mouse Tgfb1 & ATCCAGGGCCCGTATGAAA & AGGCAAATCGACAGTGTGT \\
Mouse Fcrls & AGGGCTACCATGCCAACTTC & CCACGTAGTAGACGATGGGC \\
Mouse Sall1 & AAGTGCGTTGGTGATGGC & CACAGCCACATCCCTCATGT \\
\hline
\end{tabular}

cells. Buffers used throughout this protocol were purchased as an ELISA Buffer Kit from Peprotech (Catalog \#900-K00). Briefly, IMG cells were incubated for $16 \mathrm{~h}$ with either LPS (10 ng/mL) or IL-4 (10 ng/mL) in a six-well tissue culture dish. Alternatively, IMG cells were incubated for $6 \mathrm{~h}$ with or without LPS $(10 \mathrm{ng} / \mathrm{mL})$ in $1 \mathrm{~mL}$ of full growth media at $37{ }^{\circ} \mathrm{C} 5 \% \mathrm{CO}_{2}$. Ac-YVAD-CMK $(40 \mu \mathrm{M})$ was then added to the appropriate wells for $5 \mathrm{~min}$ prior to the addition of ATP $(5 \mathrm{mM})$ for $30 \mathrm{~min}$. After the 6- or $16-\mathrm{h}$ incubation, the conditioned media were collected and the cells were washed three times with PBS and were lysed for $30 \mathrm{~min}$ at $4{ }^{\circ} \mathrm{C}$ with $1 \% \mathrm{NP}-40$ plus protease inhibitors. Appropriate capture antibody was adhered to wells of a 96-well plate overnight at room temperature. After repeated washes, the wells were blocked with $1 \%$ BSA in PBS for $1 \mathrm{~h}$ at room temperature followed by multiple washes. For each condition, $100-\mu \mathrm{L}$ aliquots of cell lysates were added to each well in triplicate for $2 \mathrm{~h}$ at room temperature. The plate was washed repeatedly, and detection antibody $(0.5 \mu \mathrm{g} / \mathrm{mL})$ was added and incubated for $1 \mathrm{~h}$ at room temperature. Plates were washed and incubated with avidin-HRP conjugate (1:2000 dilution) for $30 \mathrm{~min}$ at room temperature. Lastly, the plates were washed, and 2,2'-Azinobis [3-ethylbenzothiazoline-6-sulfonic acid]-diammonium salt (ABTS) liquid substrate was added to each well. Color development (405 nm) was monitored using a BioTek Synergy 2 spectrophotometer (Winooski, VT).

\section{IL-1 $\beta$ immunoblot}

IMG cells in a six-well poly-D-lysine-coated tissue culture dish were treated for $6 \mathrm{~h}$ with or without LPS $(10 \mathrm{ng} / \mathrm{mL})$ in $1 \mathrm{~mL}$ of full growth media at $37{ }^{\circ} \mathrm{C} 5 \%$ $\mathrm{CO}_{2}$. Ac-YVAD-CMK $(40 \mu \mathrm{M})$ was then added to the appropriate wells for 5 min prior to the addition of ATP (5 $\mathrm{mM})$ for $30 \mathrm{~min}$. The IMG cell-conditioned media were then collected and concentrated ten times from $1 \mathrm{~mL}$ to $100 \mu \mathrm{L}$ using a $10 \mathrm{~K}$ MWCO Nanosep Omega centrifugal device (PALL, Ann Arbor, MI). Seven microliters of this media was heated at $95{ }^{\circ} \mathrm{C}$ for $5 \mathrm{~min}$ and then resolved on a 4-20\% SDS-PAGE gel. The protein was then transferred onto a $0.2-\mu \mathrm{m}$ nitrocellulose membrane using a wet-transfer apparatus at $100 \mathrm{~V}$ for $60 \mathrm{~min}$. The membrane was blocked with $5 \%$ milk in TBST at $4{ }^{\circ} \mathrm{C}$ for $1 \mathrm{~h}$ prior to incubation overnight at $4^{\circ}$ $\mathrm{C}$ with goat polyclonal IL-1 $\beta$ antibody (1:500 dilution; Santa Cruz Biotechnology, Inc.). The membrane was washed three times with TBST and then was incubated for $1 \mathrm{~h}$ at room temperature with IRDye $800 \mathrm{CW}$ donkey anti-goat IgG (1:5000 dilution; Li-Cor) in TBST $3 \%$ milk. The membrane was washed three times with TBST and was imaged using Li-Cor Odyssey 2.1 infrared detection technology.

\section{Phagocytosis assays}

IMG cells were seeded into two six-well tissue culture plates $\left(0.5 \times 10^{6}\right.$ cells/well $)$ and allowed to adhere for $2 \mathrm{~h}$, after which time the media were exchanged with fresh media to remove non-adherent cells. IMG cells were allowed to grow for $16 \mathrm{~h}$ at $37{ }^{\circ} \mathrm{C} / 5 \% \mathrm{CO}_{2}$ prior to the start of the assay. Sixty-five-microliter aliquots of carboxylate-modified polystyrene fluorescent yellowgreen latex beads (YG beads) (Sigma Aldrich, Cat\# L4655) were diluted in $6.5-\mathrm{mL}$ aliquots of pre-warmed $\left(37{ }^{\circ} \mathrm{C}\right)$ or pre-chilled $\left(4{ }^{\circ} \mathrm{C}\right)$ growth media. Media were removed from IMG cells, and $1 \mathrm{~mL}$ of YG beadcontaining media was added to each well. IMG cells were immediately incubated at $37{ }^{\circ} \mathrm{C}$ or chilled at $4{ }^{\circ} \mathrm{C}$ for $1 \mathrm{~h}$. The remaining steps were strictly performed on ice. To remove non-internalized beads, cells were washed five times with $2 \mathrm{~mL} /$ well ice-cold PBS. After washing, the IMG cells were incubated with $2 \mathrm{~mL} /$ well ice-cold PBS containing $2 \mathrm{mM}$ EDTA for $10 \mathrm{~min}$ at $4{ }^{\circ} \mathrm{C}$. Cells were removed from the dish by titration and transferred to $15-\mathrm{mL}$ conical tubes. Cells were collected by centrifugation at $300 \times g$ for $6 \mathrm{~min}$ at $4{ }^{\circ} \mathrm{C}$. Cell pellets 
were resuspended in PBS containing 2 mM EDTA. IMG cell-acquired YG beads were quantified by flow cytometry, and data were analyzed.

\section{Amyloid-beta assays}

Amyloid-beta (1-42), FITC-amyloid-beta (1-42), and scrambled amyloid-beta (1-42) were purchased from rPeptide (Bogart, GA). Briefly, HFIP-prepared peptide was resuspended with DMSO $(0.1 \mathrm{mg}$ in $10 \mu \mathrm{L})$ and then diluted 1:10 with Ham's F-12 nutrient mix and incubated for $24 \mathrm{~h}$ at $4{ }^{\circ} \mathrm{C}$ as described [22, 23]. Both oligomeric and fibrillar $A \beta_{1-42}$ were detected by dot blot analyses using species-specific antibodies (Additional file 1: Figure S1). IMG phagocytosis of FITCA $\beta$ was performed using cells seeded into a 96-well black-walled amine-coated tissue culture plate. Cells were incubated with FITC-A $\beta_{1-42}(1 \mu \mathrm{M})$ at $37{ }^{\circ} \mathrm{C}$ $5 \% \mathrm{CO}_{2}$ for the times indicated in full growth medium. Cells were placed on ice and washed five times with ice-cold $\mathrm{PBS}^{++}$. One hundred microliters of $\mathrm{PBS}^{++}$was added to each well, and FITC fluorescence was measured using a plate reader (excitation $494 \mathrm{~nm}$, emission $521 \mathrm{~nm}$ ).
Indirect immunofluorescence was used to determine subcellular localization of FITC-A $\beta$. IMG cells grown on glass coverslips were incubated for $1 \mathrm{~h}$ with FITC-A $\beta$ and processed for fluorescence microscopy as described above. Briefly, cells were incubated with primary antibody targeting lysosomal-associated membrane protein 1 (LAMP1) (Pharmingen; 1:100 dilution). Secondary antirat rhodamine red antibody (JacksonImmuno Research; 1:1000 dilution) was used. Each antibody treatment was performed at room temperature for $1 \mathrm{~h}$ in $1 \%$ BSA $\mathrm{PBS}^{++}$. Cells were then washed, mounted, and imaged as described above. Co-localized pixels were determined using ImageJ $1.48 \mathrm{v}$ software (National Institute of Health, USA).

\section{Statistical analysis}

One-way ANOVA followed by Tukey's multiple comparison test was used where indicated. Two-way ANOVA followed by Dunnett's multiple comparison test was used where indicated. Paired $t$ test statistical analysis was used where indicated. Statistical analyses were performed using Prism GraphPad version 6.00 for Windows, GraphPad Software, La Jolla, CA, USA.

\section{A Immortalized adult
microglia (IMG)}

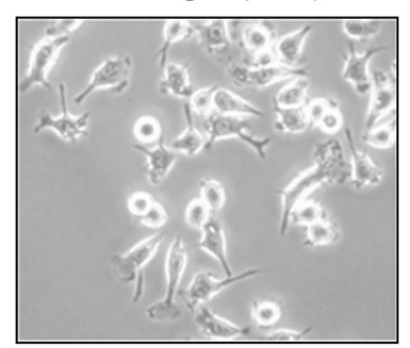

Primary adult microglia

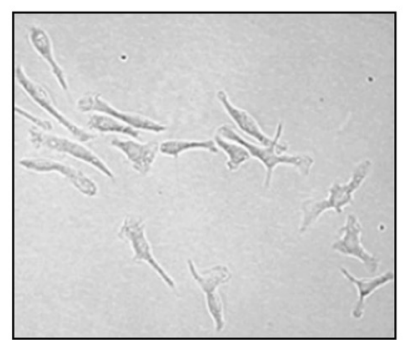

BV-2 Cells

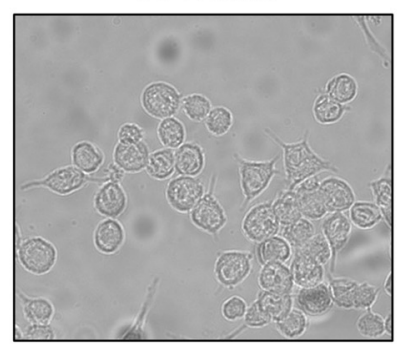

B
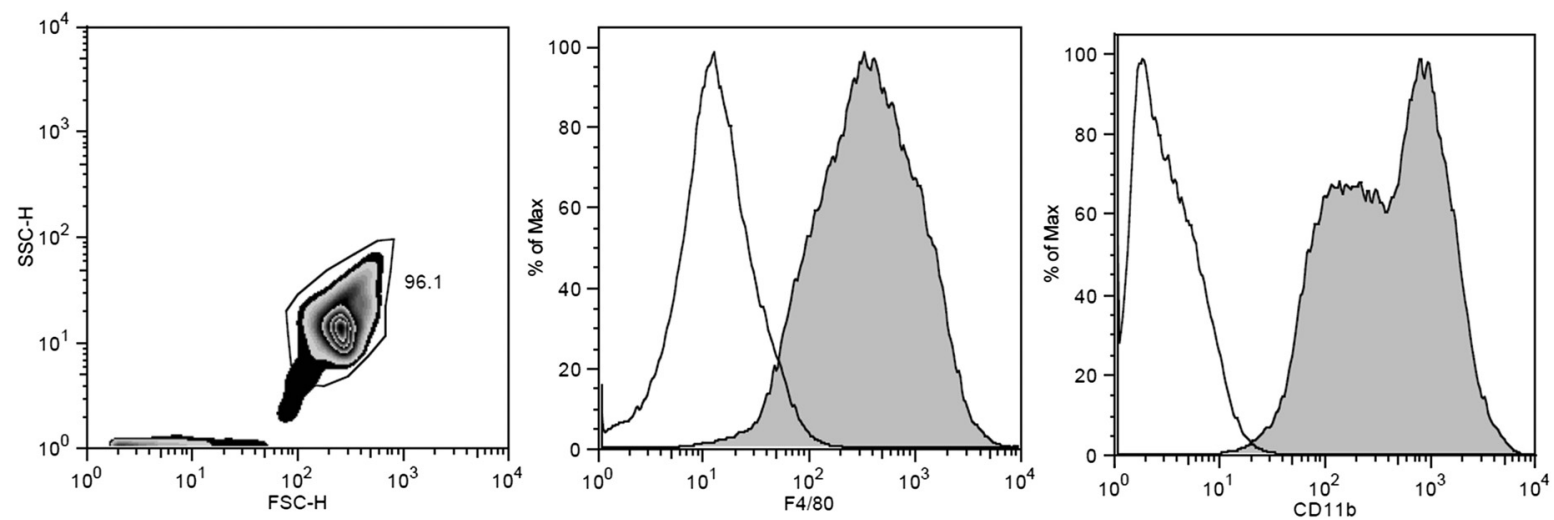

Fig. 1 IMG cells display similar morphology to primary microglia and express the microglia markers CD11b and F4/80. a Representative DIC images of IMG, BV-2, and primary adult microglial cells. Images are at $\times 40$ magnification. b Flow cytometry of IMG cells. Representative zebra plot (left panel) of IMG showing a population of >95\% was gated for the analysis of IMG F4/80 (middle panel) and CD11b (right panel) expression (filled trace) by flow cytometry. Isotype controls (open trace) are also included in the graphs 


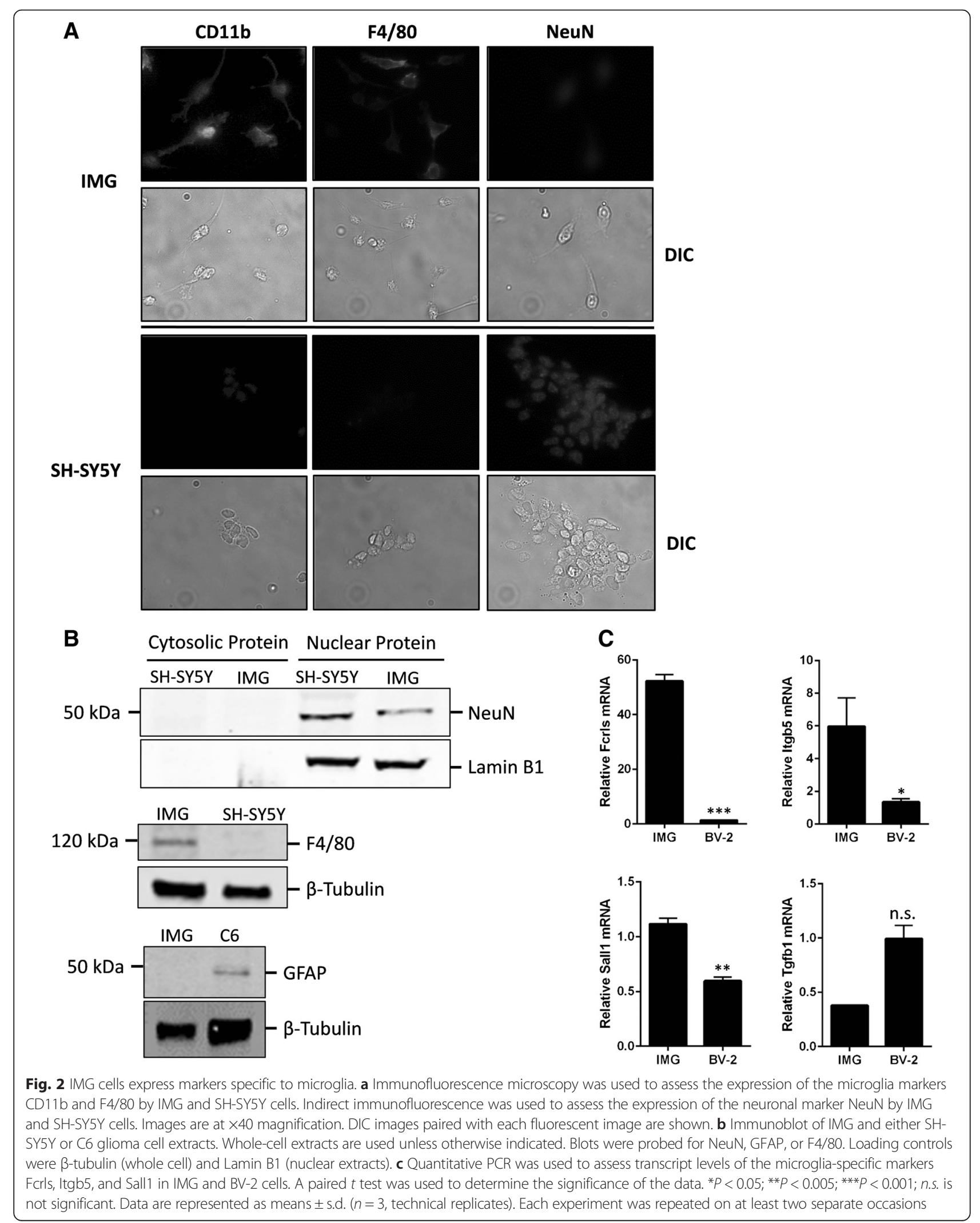




\section{Results}

IMG cells display morphology similar to primary microglia and express the microglial markers CD11b and F4/80

Phase-contrast images show that IMG, BV-2, and primary adult microglial cells are similar in cell morphology and size (Fig. 1a). The morphology of microglia is dependent upon their activation state; activated or dividing microglia are amoeboid-shaped whereas resting microglia display a ramified morphology [24] Both IMG and BV-2 are rapidly dividing immortalized cells containing mostly amoeboid (dividing) with few ramified cells.

Expression of two microglia-specific markers, CD11b and F4/80, was determined by flow cytometry [3]. Both CD11b and F4/80 are detected in mouse brain after embryonic day $9.5[16,25]$. Indeed, these markers are expressed by IMG cells as indicated by flow cytometry (Fig. 1b; filled trace); isotype controls are used to account for non-specific binding (Fig. 1b; open trace). We further confirmed the expression of CD11b and F4/80 using fluorescence microscopy (Fig. 2a); both CD11b and F4/80 were detected in IMG cells but not in SH-SY5Y cells, a neuronal cell line. Conversely, the neuron-specific marker NeuN was detected in SH-SY5Y cells and to a lesser extent in IMG cells (Fig. 2b). Western blot analysis confirmed NeuN staining was specific, as some protein was detected in IMG nuclear extracts. Western blot analysis also detected the astrocyte-specific marker GFAP in C6 glioma cell lysates but not in IMG cell lysates (Fig. 2b). Recent work has identified several genes unique to adult microglia [26]. Transcript levels of three of the four genes tested (Fcrls, Itgb5, Sall1, and Tgfb1) are significantly greater in IMG cells compared to BV-2 cells (Fig. 2c). These combined data suggest that IMG cells are a pure population with both morphology and biomarkers associated with adult microglia [16].

\section{IMG cells respond to exogenous pro- and anti- inflammatory stimuli}

Adult microglial cells characteristically polarize to either pro- or anti-inflammatory state in response to alterations in their local microenvironment [1]. A number of signaling molecules have been identified that induce reactive/reparative polarization of microglial cells. IMG cells were exposed for 8 or $24 \mathrm{~h}$ to induce either the reactive pro-inflammatory phenotype (LPS, IFN $\gamma$, IL- $1 \beta$, and TNF- $\alpha$ ) or the reparative anti-inflammatory phenotype (IL-4 and IL-13) [1, 3]. After incubation with the appropriate signaling molecules, RNA was isolated and qPCR was performed to determine the state of IMG activation. Markers indicative of reactive polarization that were assessed via qPCR included inducible nitric oxide synthase (iNOS), TNF- $\alpha$, and IL-1 $\beta$ transcripts while markers indicative of the anti-inflammatory response included Arg-1, Mgl1, and Ym1 transcripts. The results show that IMG cells transition to a reactive phenotype when incubated for 8 or $24 \mathrm{~h}$ with LPS, IFN $\gamma$, and to a lesser extent IL-1 $\beta$ and TNF- $\alpha$ (Fig. 3a). Conversely, IMG cells express anti-inflammatory markers when incubated for 8 or $24 \mathrm{~h}$ with IL-4 and IL-13 (Fig. 3b). As similar changes in transcript abundance were noted in IMG cells treated with stimuli for 8 or $24 \mathrm{~h}$, we performed all incubations with LPS or IL-4 for a period of $16 \mathrm{~h}$ in later experiments. Taken together, these data indicate that IMG cells retain the ability to polarize to the pro- or anti-inflammatory state, a functional feature of microglia that is well-documented by the literature [1].

As IMG cells are activated by incubation with LPS (Fig. 3a), we hypothesized protein production of secreted pro-inflammatory factors would increase. To test this, an ELISA was used to determine relative abundance of the cytokines IL- 6 and TNF- $\alpha$ in IMG cell-conditioned media after incubation with LPS. ELISA results confirmed that exposure to LPS for $16 \mathrm{~h}$ yielded a significant increase in IL-6 and TNF- $\alpha$ (Fig. 4a); no significant change in expression of these cytokines was noted when cells were exposed to IL-4 for $16 \mathrm{~h}$. LPS also increased synthesis of IL-1 $\beta$, detected by ELISA in IMG cell lysates (Fig. 4b). Inflammasome activation and caspase-1mediated cleavage of pro-IL- $1 \beta$ is required for secretion of mature IL- $1 \beta$ by LPS-primed microglia [27]. Activation of the NLRP3 inflammasome in LPS-primed IMG cells by treatment with ATP significantly enhanced secretion of IL-1 $\beta$ into conditioned media (Fig. 4c); addition of the caspase-1 inhibitor Ac-YVAD-CMK abrogated this effect. Treatment of LPS-primed IMG cells with ATP resulted in processing and secretion of the 17$\mathrm{kDa}$ mature form of IL- $1 \beta$ into the media (Fig. $4 \mathrm{~d}$ ). Cleavage to the mature form was inhibited by AcYVAD-CMK (Fig. 4d). Thus, LPS upregulates synthesis, processing, and secretion of mature IL-1 $\beta$ by IMG cells in an appropriate two-step process.

\section{IMG cells display a more robust response than BV-2 cells} to pro- and anti-inflammatory stimuli

BV-2 cells have been often used to examine microglial cell function. However, this cell line responds poorly to pro- and anti-inflammatory stimuli (LPS and IL-4, respectively) [14, 28-31]. We directly compared IMG and BV-2 responses to LPS or IL-4 upon 16-h exposure. Transcript abundance of both iNOS and Arg-1 was monitored via qPCR (Fig. 5). IMG cells increase the production of iNOS ( $>200$-fold) or Arg-1 (>100-fold) transcripts compared to BV-2 cells upon exposure to either LPS or IL-4, respectively. 

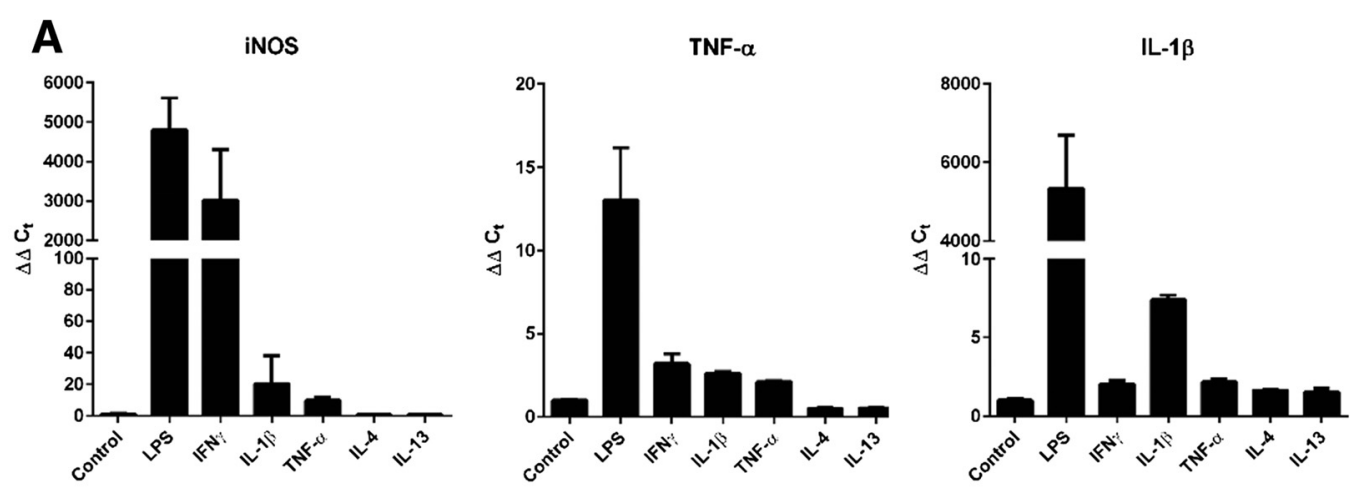

$8 h$
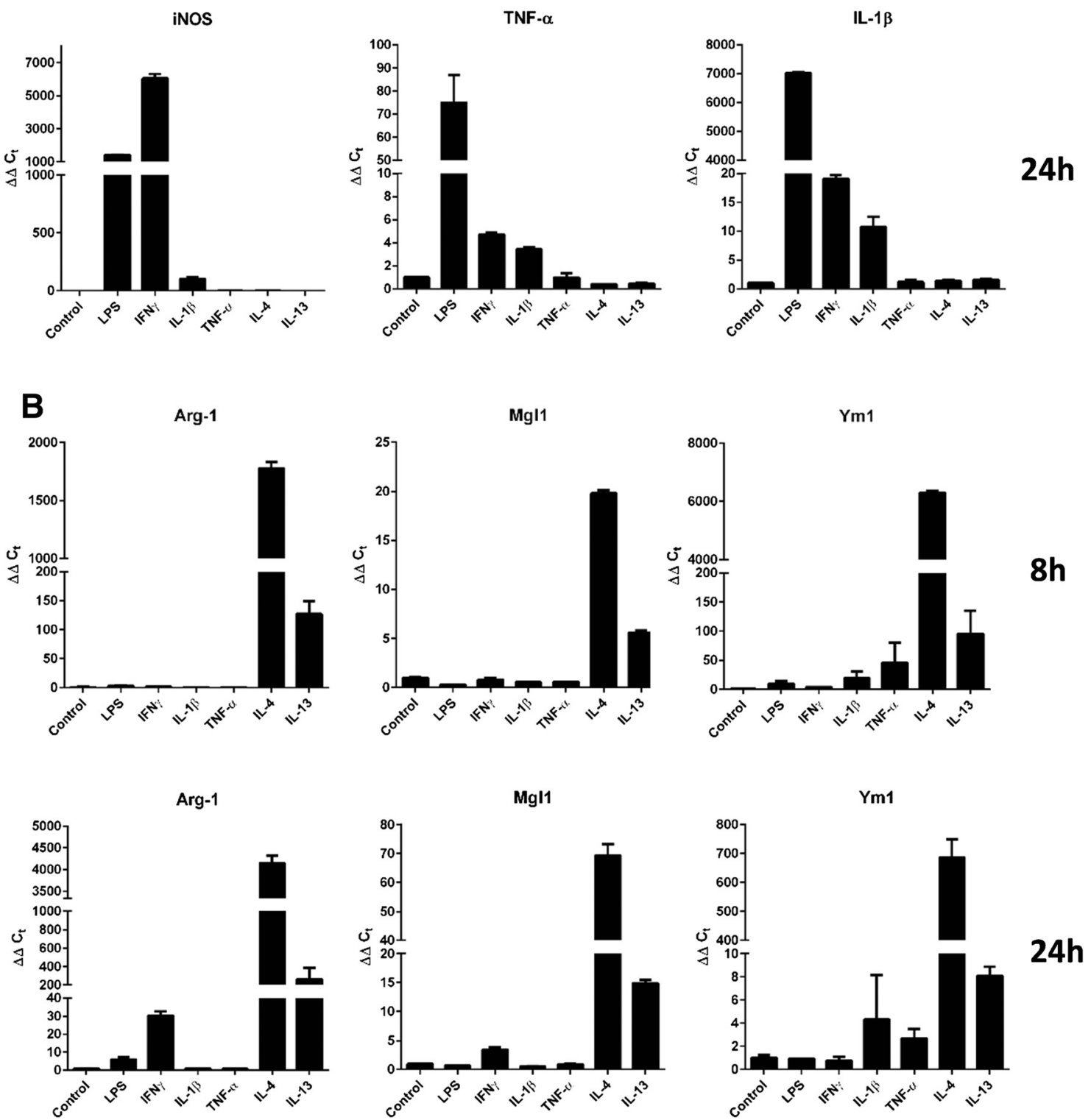

Fig. 3 (See legend on next page.) 
(See figure on previous page.)

Fig. 3 Response of IMG cells to pro- and anti-inflammatory stimuli. IMG cells were treated for either 8 or $24 \mathrm{~h}$ with LPS (10 $\mathrm{ng} / \mathrm{mL})$, interferon gamma (IFNy) $(10 \mathrm{ng} / \mathrm{mL}), I L-1 \beta(10 \mathrm{ng} / \mathrm{mL})$, TNF-a $(5 \mathrm{ng} / \mathrm{mL}), \mathrm{LL}-4(10 \mathrm{ng} / \mathrm{mL}), I L-13(10 \mathrm{ng} / \mathrm{mL}), I L-6(10 \mathrm{ng} / \mathrm{mL})$, or TGF- $\beta$ (50 ng/mL). iNOS, TNF$a$, and IL-1 $\beta$ message levels were used as markers for the microglial pro-inflammatory phenotype (a), whereas Arg-1, Mgl1, and Ym1 were used as markers for an anti-inflammatory phenotype (b). Quantitative PCR was used to assess the changes in message levels of the aforementioned genes relative to the internal control 36B4. Average of biological duplicates are shown with similar results obtained in at least two different experiments

In the Alzheimer's brain, microglia are polarized to a reactive state by $A \beta$ peptides in the interstitium. We compared the efficacy of $A \beta$ on iNOS production in IMG and BV-2 cells. The transcript abundance of iNOS within both IMG and BV-2 cells increased as a consequence of increasing $A \beta$ concentration (Fig. 5b, c); scrambled $A \beta$ peptide had no measurable effect. Notably, the increase in $A \beta$-induced iNOS expression by IMG cells (approx. 2500-fold at $5 \mu \mathrm{M} \mathrm{A} \beta$ ) was far greater than that observed in BV-2 cells (approx. 350fold at $5 \mu \mathrm{M} A \beta)$. IMG cell nitrite production was increased with $A \beta$ treatment as determined by the Griess assay (data not shown).

\section{IMG cells phagocytose foreign particles}

When confronted with foreign particles such as dead or dying neurons, microglia will remove these materials via phagocytosis $[11,32]$. To test their phagocytic potential, IMG cells were exposed to $1-\mu \mathrm{m}$-diameter carboxylatemodified polystyrene fluorescent YG beads for $1 \mathrm{~h}$ at $37^{\circ} \mathrm{C}$. Internalization of the YG beads by IMG cells was evaluated by fluorescence microscopy. A series of z-
A

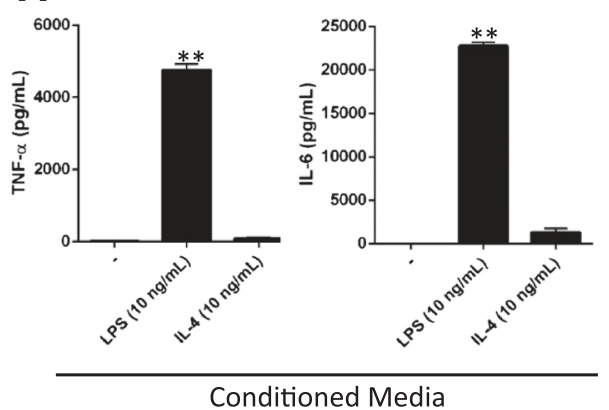

B
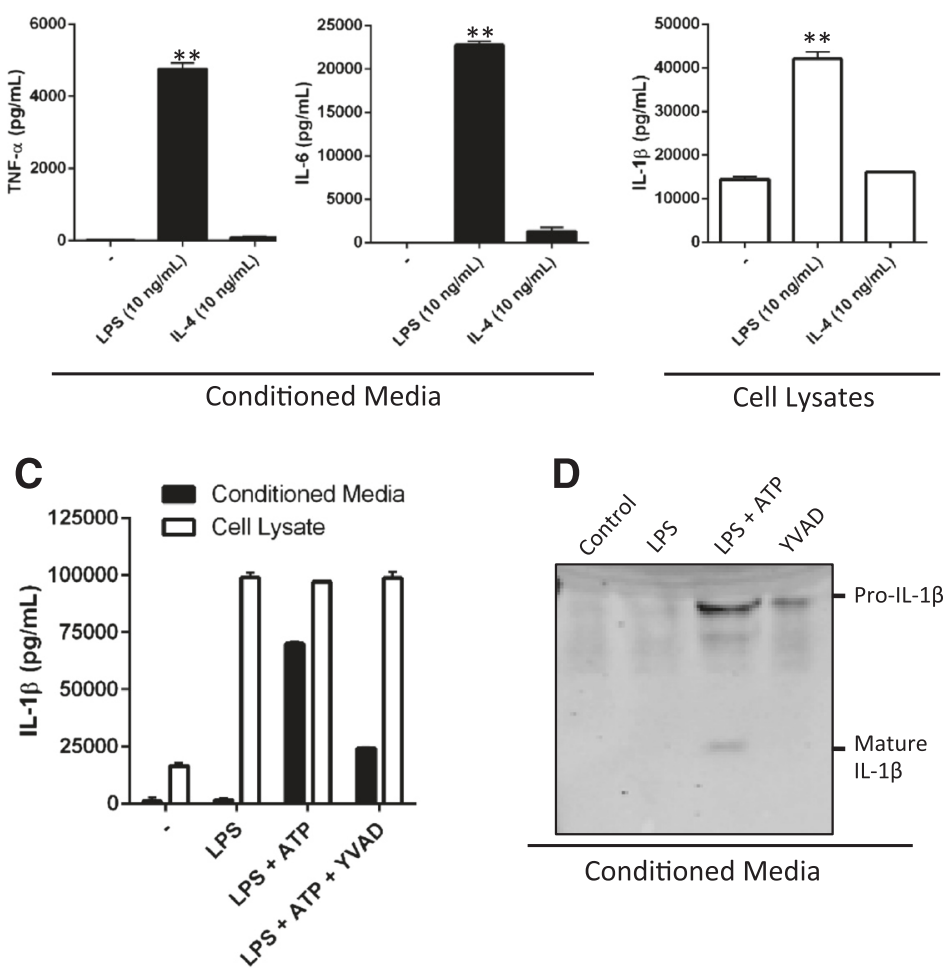

D

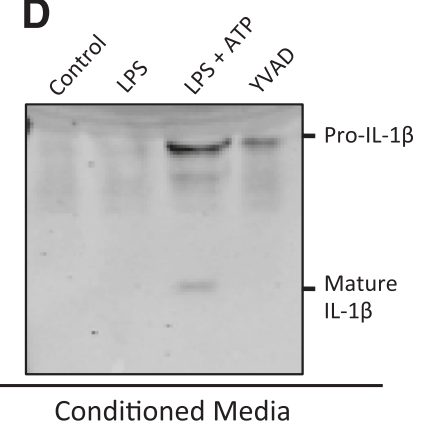

Fig. 4 IMG cells respond to LPS treatment by increasing protein expression of inflammatory cytokines. a ELISA was used to analyze the secretion of TNF- $\alpha$ and IL-6 into IMG cell-conditioned medium during a 16-h incubation with or without LPS (10 ng/mL) or IL-4 (10 ng/mL) as described in the "Methods" section. $\mathbf{b}$ ELISA analysis of IL-1 $\beta$ in whole-cell lysates of IMG cells treated as described in (a). c ELISA of conditioned media (filled bars) and cell lysates (open bars) collected from IMG cells treated with or without LPS (10 ng/mL) for $6 \mathrm{~h}$. LPS-treated cells were also incubated

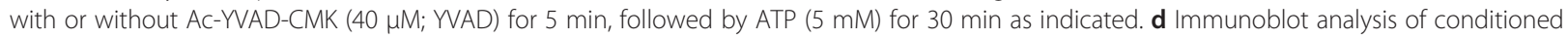
media from IMG cells treated as described in (c). Blots were probed for IL-1 $\beta$. Pro- $(34 \mathrm{kDa})$ and mature $(17 \mathrm{kDa}) \mathrm{IL}-1 \beta$ bands are indicated. One-way ANOVA was used to determine the significance of the data. ${ }^{*} P<0.01$; ${ }^{*} P<0.0001$. Data are represented as means \pm s.d. $(n=3$, technical replicates). Each experiment was repeated on at least two separate occasions 

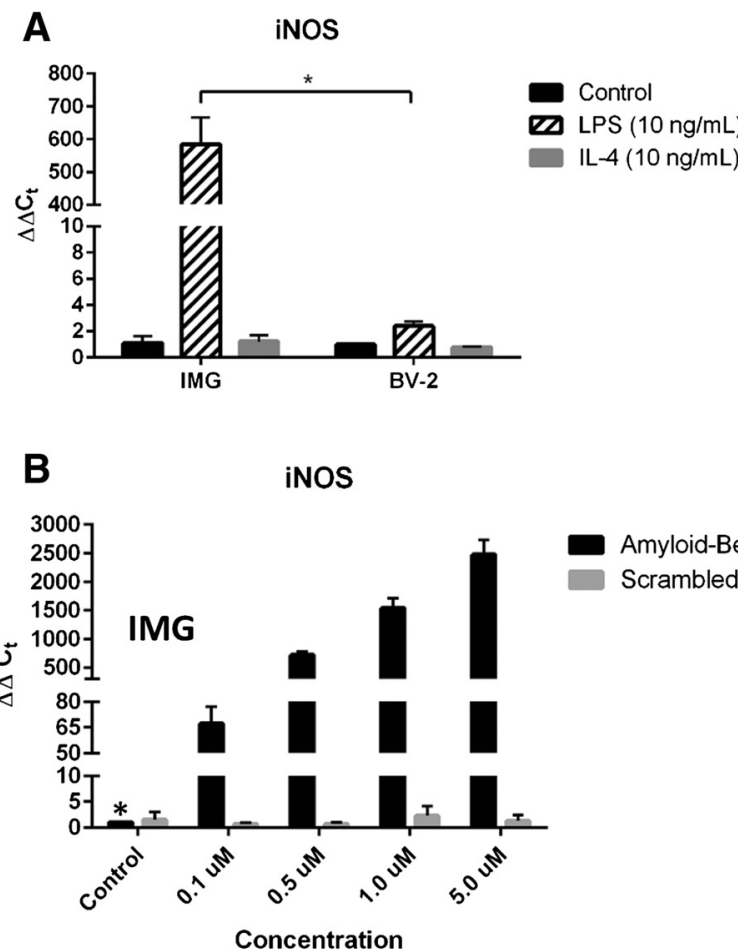

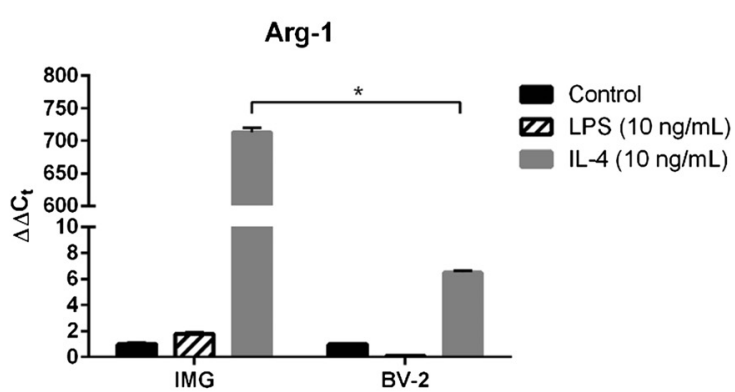

C iNOS

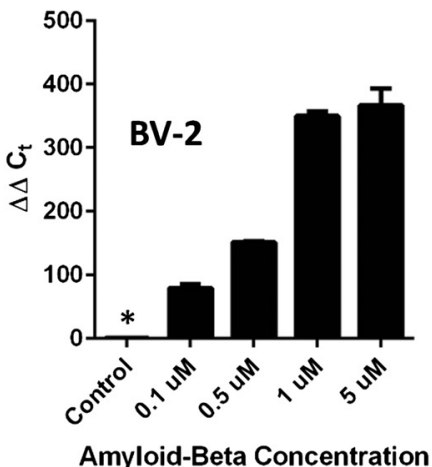

Fig. 5 IMG cells are significantly more sensitive to polarization by LPS, AB, and IL-4 than are BV-2 cells. a Quantitative PCR was used to analyze the transcript abundance of iNOS and Arg-1 in IMG cells and BV-2 cells treated with or without LPS (10 ng/mL) or IL-4 (10 ng/mL) for 16 h. $\mathbf{b}, \mathbf{c}$ IMG and BV-2 cells were treated with $A \beta_{1-42}$ peptide or scrambled $A \beta_{1-42}$ peptide at varying concentrations as indicated for 6 h. The transcript abundance of iNOS was determined via GPCR. One-way (b) and two-way (a) ANOVA statistical analyses were used to determine the significance of the data. ${ }^{*} P<0.0001$. Data are represented as means \pm s.d. ( $n=3$, technical replicates). Each experiment was repeated in triplicate

stack images were acquired to examine the localization of YG beads (shown in green) within a single IMG cell (identified by the microglial marker CD11b (purple)) (Fig. 6a). The compilation of images provided by the zstack clearly indicates that this particular IMG cell engulfed at least two YG beads, as shown by their intracellular localization (Fig. 6a, arrows). Cross-sectional images of the same IMG cell are shown in Fig. $6 \mathrm{~b}$.

Next, we used flow cytometry to quantify the number of beads phagocytosed per IMG cell. Again, IMG cells were incubated with YG beads for $1 \mathrm{~h}$ at $37{ }^{\circ} \mathrm{C}$ to allow time for phagocytosis to occur. Simultaneously, a dish of IMG cells was incubated with YG beads for $1 \mathrm{~h}$ at $4{ }^{\circ} \mathrm{C}$ to account for non-specific binding. After exposure to YG beads, IMG cells were washed thoroughly and analyzed for yellow-green fluorescence via flow cytometry. By monitoring the degree of fluorescent intensity, populations of IMG cells which have ingested $0,1,2,3$, or 4 beads can be differentiated (Fig. 7a, see labels in the middle graph). These data are quantitatively similar to phagocytosis of YG beads by BV-2 cells (Fig. 7b, c).

In the Alzheimer's brain, a major function of microglial is to clear $A \beta$ by phagocytosis. To study uptake of $\mathrm{A} \beta$, IMG cells were incubated at $37^{\circ} \mathrm{C}$ with $1 \mu \mathrm{M}$ FITC-
$\mathrm{A} \beta$ for the indicated times and washed, and then internalization was analyzed using a fluorescence plate reader. These data show that IMG phagocytosis of FITC-A $\beta$ is time-dependent and maximal within $3 \mathrm{~h}$ (Fig. 7d). We hypothesized that a portion of the $A \beta$ phagocytosed by IMG cells would be trafficked to the phagolysosome within this time frame. Immunofluorescence microscopy confirmed that a fraction of the FITC-A $\beta$ phagocytosed by IMG during a 1 -h incubation period co-localized with the LAMP1 (Fig. 7e).

\section{$A \beta$-induced iNOS expression by IMG cells is blocked by cannabinoids}

Since IMG cells display the same characteristics as primary microglia, the idea that this cell model system could be used for candidate drug screens in the treatment of Alzheimer's disease is well-supported. To evaluate their use in pharmacological studies, we examined the effects of the cannabinoids THC and JWH-015 on A $\beta$-induced iNOS gene expression. Prolonged use of cannabinoids is reported to reduce inflammation in the brains of Alzheimer's disease model mice [33]; cannabinoids have also been shown to reduce microglial activation both in vitro and in vivo $[34,35]$. The principal 
A

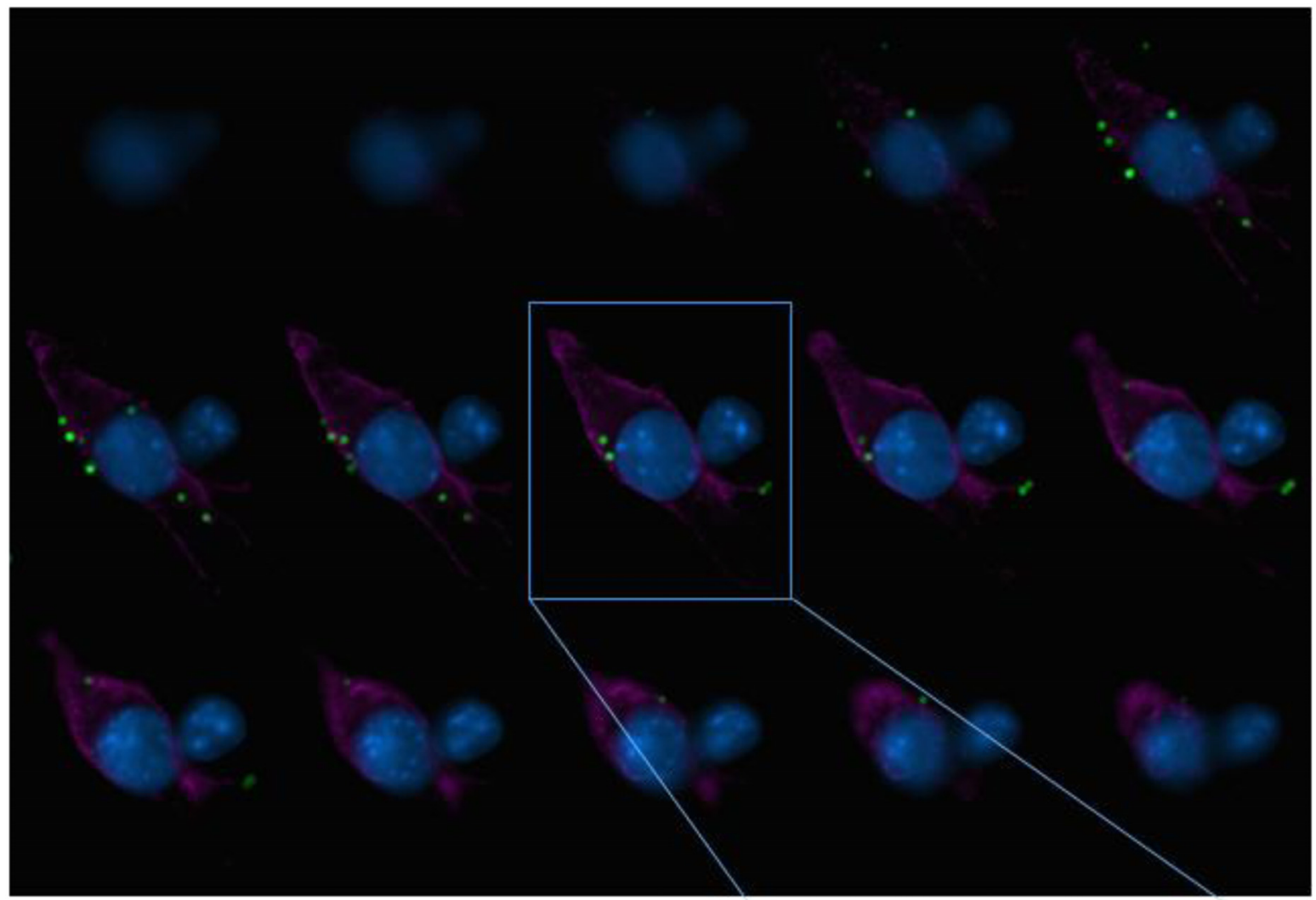

B
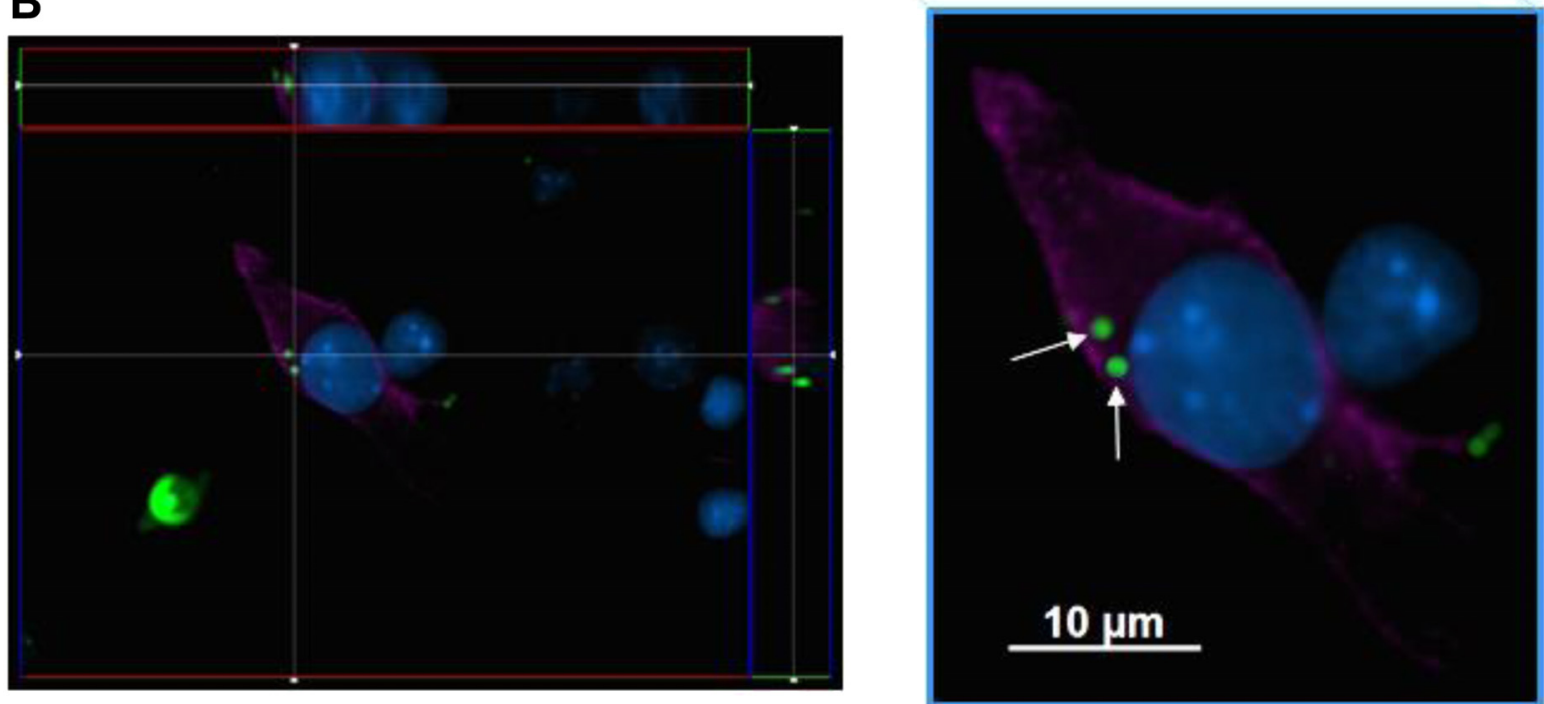

Fig. 6 IMG cells internalize fluorescent latex beads. Images of IMG cells that were incubated with fluorescent latex beads for $1 \mathrm{~h}$ at $37^{\circ} \mathrm{C} 5 \% \mathrm{CO}_{2}$ were obtained. CD11b (purple) was used as a marker for IMG cells. a Z-stack series of microscopic images of an IMG cell (purple) were compiled into a grid to demonstrate the internal localization of two fluorescent latex beads (green dots; indicated by arrows). b Z-stack series from (a) is accompanied by two cross-sectional perspectives. The images were obtained with a $\times 100$ objective. DAPI (blue) stains the nucleus

psychoactive constituent of cannabis, THC, significantly inhibited the $A \beta$-induced increase in iNOS transcript levels within IMG cells (Fig. 8a). THC is an agonist to both cannabinoid receptor type 1 ( $\mathrm{CB}_{1}$; psychoactive) and type $2\left(\mathrm{CB}_{2}\right.$; non-psychoactive). JWH-015 is a selective $\mathrm{CB}_{2}$ agonist. Like THC, JWH-015 $(50 \mu \mathrm{M})$ inhibited 

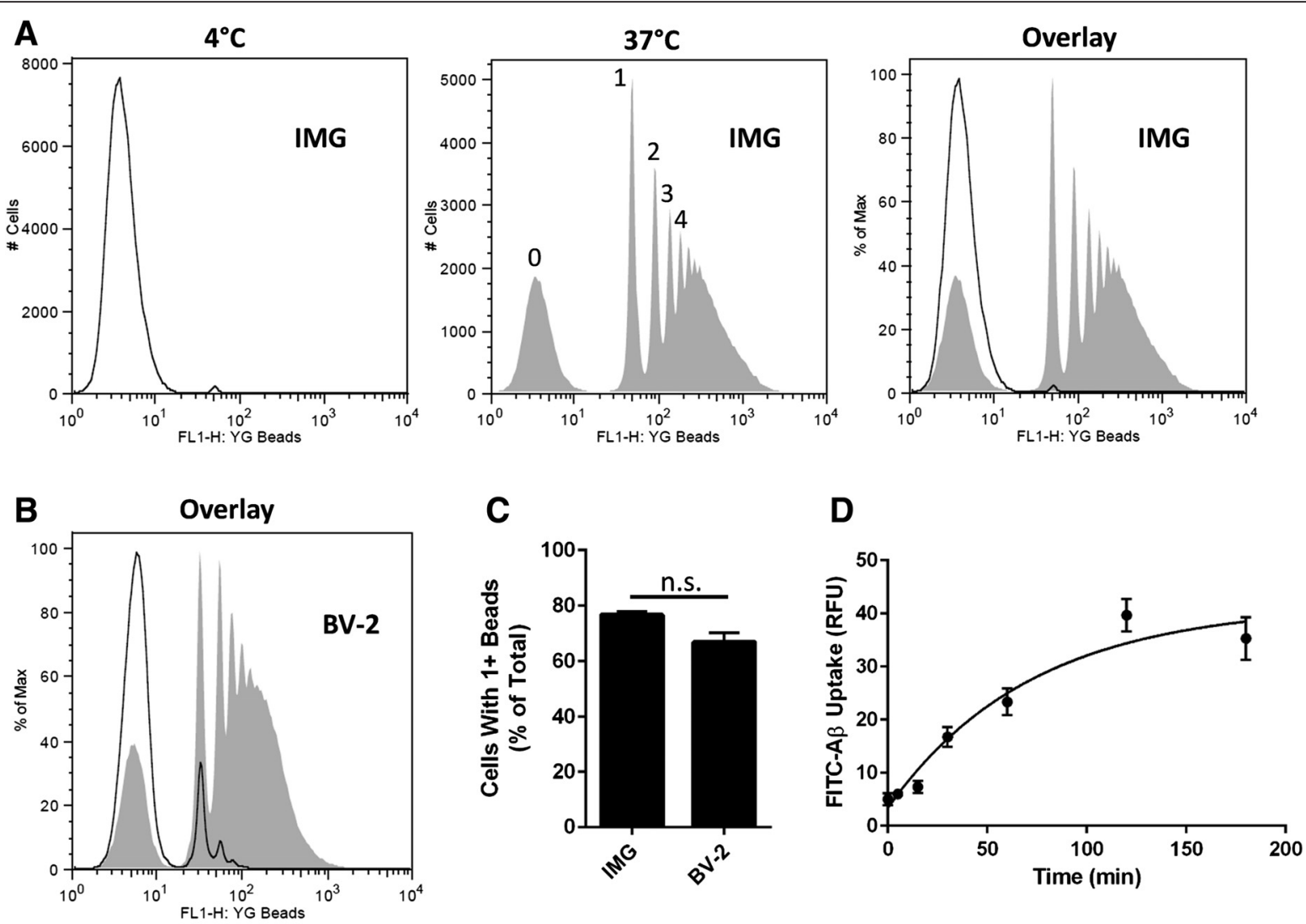

\section{E}
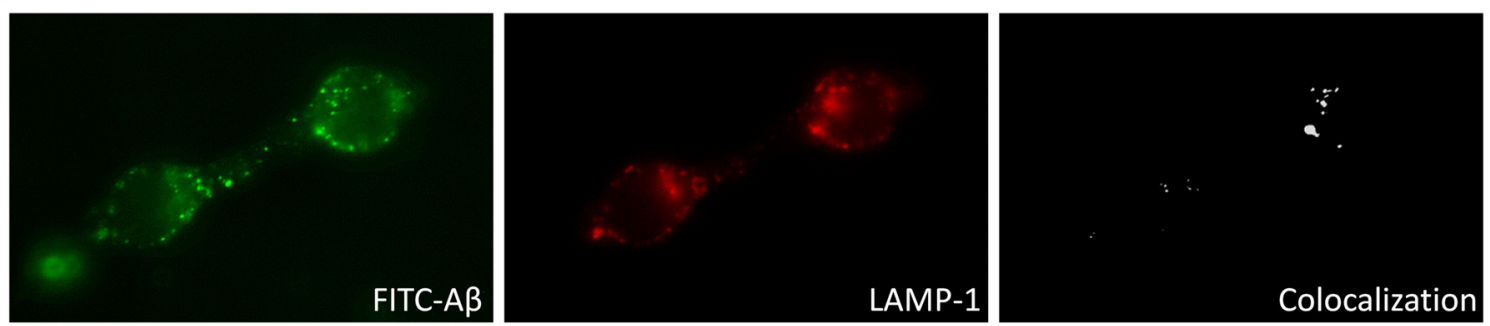

Fig. 7 IMG cells retain phagocytic properties inherent in microglial cells. Phagocytosis of 1- $\mu \mathrm{m}$ fluorescent yellow-green latex beads (YG beads) by IMG (a) or BV-2 (b) cells as analyzed by flow cytometry. Cells were incubated with the YG beads for $1 \mathrm{~h}$ at either $4{ }^{\circ} \mathrm{C}$ (open trace) or $37^{\circ} \mathrm{C}$ (gray fill) prior to analysis by flow cytometry. Each peak represents the IMG population which has ingested either 0, 1, 2, 3, or 4 beads, respectively. Each graph (a, b) is a representation of data from at least three biological replicates. $\mathbf{c}$ Percentage of cells which acquired $\geq 1$ YG beads as analyzed by flow cytometry. $\mathbf{d}$ Kinetic analysis of oligomeric FITC-A 3 uptake by IMG. IMG cells were incubated with FITC-A $(1 \mu \mathrm{M})$ for the indicated times at $37^{\circ} \mathrm{C}$. IMG-associated FITC fluorescence was measured using a plate reader. e Subcellular localization of internalized FITC-A $\beta$ was assessed using fluorescence microscopy. IMG cells were incubated for $1 \mathrm{~h}$ with FITC-Aß (green) prior to being processed for microscopy. Phagolysosomes were identified using LAMP1 antibody (red). Areas of co-localization (white) were determined using ImageJ software. A paired $t$ test was used to determine the significance of the data (n.s. is not significant). Data are represented as means \pm s.d. ( $(n=3$, experimental replicates)

$\mathrm{A} \beta$-induced iNOS expression and in a time-dependent manner (Fig. 8b). In a dosing experiment, we determined the effect of JWH-015 on A $\beta$-induced IMG iNOS levels is reproducible even at a lower dose $(5 \mu \mathrm{M})$ (Fig. 8c). Neither drug altered the expression of the M2 marker Arg- 1 in A $\beta$-treated IMG cells (data not shown). These data are consistent with previous results in the literature demonstrating cannabinoid-mediated prevention of $A \beta-$ induced microglial activation [35]. Combined, this evidence demonstrates the pharmacological intervention of A $\beta$-induced M1 activation of IMG cells.

\section{Discussion}

Chronically activated pro-inflammatory adult microglial cells contribute to the progression of neurodegenerative diseases like Alzheimer's and Parkinson's 

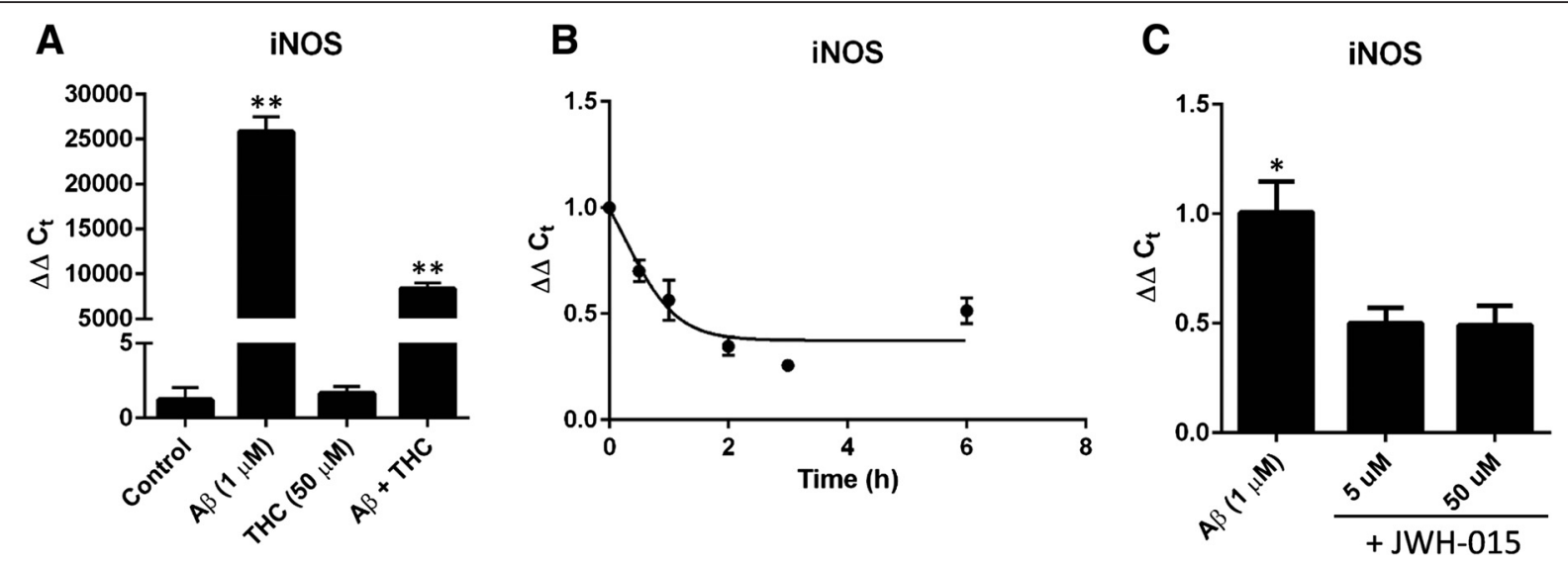

Fig. 8 Cannabinoids inhibit A $\beta$-induced iNOS production in IMG cells. Quantitative PCR was used to analyze the transcript abundance of iNOS in IMG cells. a IMG cells were treated with or without $A \beta$ and/or THC for $6 \mathrm{~h}$ at $37^{\circ} \mathrm{C}$. IMG cells were incubated with $A \beta$ ( $1 \mu \mathrm{M}$; $6 \mathrm{~h}$ ) and the $\mathrm{CB} 2$ selective agonist JWH-015 (50 $\mu \mathrm{M})$ for the indicated times (b) or at varying concentrations (c). One-way ANOVA statistical analyses were used to determine the significance of the data. ${ }^{*} P<0.005 ;{ }^{*} P<0.0001$. Data are represented as means \pm s.d. ( $n=3$, technical replicates)

diseases $[4,5,9,10]$. An adult immortalized microglial cell model system for examination of neuroinflammation is therefore essential. BV-2 cells, a currently used model system, were generated using mononuclear cells from an embryonic mouse brain. A major drawback is the limited BV-2 cell response to pro- and anti-inflammatory stimuli (Fig. 6) $[14,15,29-31]$. On the other hand, primary adult microglial cell isolation yields a limited number of cells, can be technically challenging with potential cell activation, and suffers from a lack of homogeneity.

Here, we describe the development of a novel immortalized adult microglial cell line, IMG cells, which share phenotypic attributes with primary adult microglia and respond robustly to inflammatory signals. Primary adult microglia react to changes in their extracellular environment by polarizing to a reactive phenotype or one that promotes resolution of inflammation [10, 36]. IMG cells are far more responsive than BV-2 cells to external pro- and anti-inflammatory signals such as LPS and IL-4. The fact that IMG cells display a robust response to external proand anti-inflammatory stimuli make this an ideal model system to examine microglial involvement in neurodegenerative diseases, such as Alzheimer's disease, where a link between chronic microglial activation and the progression of the disease has been well established $[5,37]$.

In the early stages of Alzheimer's disease, brain microglia become activated by $\mathrm{A} \beta$ peptides which, in turn, are cleared by the microglia via phagocytosis $[11,38-40]$. The activation of microglia by $A \beta$ peptides increases secretion of pro-inflammatory cytokines, which can reduce microglial cell $A \beta$ peptide receptor expression via an autocrine feedback loop $[38,41]$. The reduced expression of $A \beta$ receptors by microglia results in reduced clearance, thus promoting plaque formation to persist and disease progression to continue. Secretion of pro-inflammatory cytokines by activated microglia also promotes neuronal cell damage and death. It is therefore important to understand microglial cell function, especially $A \beta$-induced activation and phagocytosis, in order to develop new therapies aimed at targeting these pro-inflammatory effects. We have developed and characterized the IMG cell line to advance towards these goals.

Taming the chronic pro-inflammatory polarization of microglia in Alzheimer's disease is one therapeutic strategy that is actively investigated [2]. In the past, BV-2 cells have been used to screen for potential anti-inflammatory drugs to quell or negate the effect of LPS [30]. Our experiments show that the IMG cells' response to inflammatory factors is far greater than that of BV-2 cells, raising the promise of their utility in such screening efforts. Moreover, IMG cells are highly reactive to $A \beta$, establishing an in vitro model relevant to Alzheimer's disease. To explore their potential use in pharmacological studies, we established that the cannabinoids THC and JWH-015 limit $\mathrm{A} \beta$-induced IMG cell inflammation. The mechanism of anti-inflammatory action of cannabinoids has yet to be established, but our studies suggest CB2 activation by the selective agonist JWH-015 is sufficient to mediate this effect. In preliminary experiments, we have determined that cannabinoids do not alter $A \beta$ uptake or degradation by IMG cells (data not shown). CB2 may elicit downstream signals to reduce the $A \beta$-induced inflammatory response in IMG cells. Potential targets include elements of the peroxisome proliferator-activated receptor- $\gamma$ (PPAR- $\gamma$ ) pathway [42]. Further investigation is required to determine the exact mechanism of 
cannabinoid drug action on IMG cells and to employ these cells to screen for new drug candidates that ameliorate $A \beta$-induced inflammation.

\section{Conclusions}

We have established an immortalized cell line from adult murine microglia. We conclude this model system, called IMG for immortalized microglia, fully recapitulates morphological and functional characteristics of brain microglia. IMG cells express microglia-specific markers and respond appropriately to pro- and antiinflammatory stimuli. IMG cells phagocytose foreign particles. Moreover, IMG cells are robustly activated by $A \beta_{1-42}$, which they also phagocytose. The response of IMG cells to extracellular pro- and anti-inflammatory stimuli, including $A \beta$, is far greater than the most commonly employed microglial BV-2 cell line. As an example of their potential utility, we demonstrate administration of cannabinoids can effectively alleviate A $\beta$ activation of IMG cells. This cell line provides a new platform to explore drug interactions and gain mechanistic information about neuroinflammatory responses underlying Alzheimer's disease and other neurological disorders.

\section{Additional file}

Additional file 1: Figure S1. Dot blot analyses using species-specific antibodies. Preparation of $A \beta$ contains both oligomeric and fibrillar $A \beta$. Immunoreactivity of dot blots of $A \beta$ scrambled (A $\mathrm{sscr}$ ) or $A \beta 1-42$ was detected using 4G8, A11, or OC antibodies as described in the "Methods" section. Scrambled A $\beta$ demonstrates antibody specificity. (PDF 155 KB)

\section{Competing interests}

The authors declare that they have no competing interests.

\section{Authors' contributions}

$\mathrm{D}-\mathrm{YL}$ and $\mathrm{C}-\mathrm{HL}$ isolated the primary microglia, generated the IMG cell line, and obtained the phase-contrast images for each. AA designed and carried out the cytokine panel experiments on the IMG cells used for the qPCR analysis. AMG performed all of the QPCR and flow-cytometry analyses. RCM wrote the manuscript, participated in the study's design and coordination, and performed the flow-cytometry, ELISA, western blot, indirect immunofluorescence, phagocytosis, BV-2, and A $\beta$ analyses. MW-R and C-HL conceived the study, participated in its design and coordination, and helped to draft the manuscript. All authors read and approved the final manuscript.

\section{Acknowledgements}

This study was supported by the National Institutes of Health grants from the National Institute of Environmental Health Sciences to MW-R (R01 ES0146380) and the National Institute of Diabetes and Digestive and Kidney Diseases to C-HL (R01 DK075046). RCM is supported by the National Institute of Environmental Health Sciences grant T32 ES016645. We thank Dr. Daniel J. Kosman for his generous donation of the C 6 glioma cells and GFAP antibody. IMG cells have been deposited at KeraFAST.

\section{Author details}

${ }^{1}$ Department of Genetics and Complex Diseases, Harvard School of Public Health, 655 Huntington Avenue, Boston, MA 02115, USA. P2Present Address: Graduate Institute of Neural and Cognitive Sciences, China Medical University, Taichung, Taiwan, Republic of China. ${ }^{3}$ Present Address: The Wellman Center for Photomedicine, Massachusetts General Hospital and Harvard Medical School, Boston, MA, USA.
Received: 27 July 2015 Accepted: 18 January 2016

Published online: 27 January 2016

\section{References}

1. Hu X, Leak RK, Shi Y, Suenaga J, Gao Y, Zheng P, et al. Microglial and macrophage polarization—-new prospects for brain repair. Nat Rev Neurol. 2015;11(1):56-64. doi:10.1038/nrneurol.2014.207.

2. Cherry JD, Olschowka JA, O'Banion MK. Neuroinflammation and M2 microglia: the good, the bad, and the inflamed. J Neuroinflammation. 2014;11(98):15.

3. Greter M, Merad M. Regulation of microglia development and homeostasis. Glia. 2013;61(1):121-7. doi:10.1002/glia.22408.

4. Perry VH, Nicoll JAR, Holmes C. Microglia in neurodegenerative disease. Nat Rev Neurol. 2010;6(4):193-201.

5. Perry VH, Holmes C. Microglial priming in neurodegenerative disease. Nat Rev Neurol. 2014;10(4):217-24. doi:10.1038/nrneurol.2014.38.

6. Li Y, Tan M-S, Jiang T, Tan L. Microglia in Alzheimer's disease. BioMed Res Int. 2014;2014:7. doi:10.1155/2014/437483.

7. Oberstein TJ, Spitzer $P$, Klafki H-W, Linning P, Neff F, Knölker H-J, et al. Astrocytes and microglia but not neurons preferentially generate $\mathrm{N}$ terminally truncated A $\beta$ peptides. Neurobiol Dis. 2015;73(0):24-35. http://dx. doi.org/10.1016/j.nbd.2014.08.031.

8. Orre M, Kamphuis W, Osborn LM, Jansen AHP, Kooijman L, Bossers K, et al. Isolation of glia from Alzheimer's mice reveals inflammation and dysfunction. Neurobiol Aging. 2014;35(12):2746-60. http://dx.doi.org/10. 1016/j.neurobiolaging.2014.06.004.

9. Brown $\mathrm{G}$, Neher J. Inflammatory neurodegeneration and mechanisms of microglial killing of neurons. Mol Neurobiol. 2010;41(2-3):242-7. doi:10.1007/ s12035-010-8105-9.

10. Tang $Y$, Le $W$. Differential roles of $m 1$ and $m 2$ microglia in neurodegenerative diseases. Mol Neurobiol. 2015:1-14. doi:10.1007/s12035-014-9070-5.

11. Yu Y, Ye R. Microglial A $\beta$ receptors in Alzheimer's disease. Cell Mol Neurobiol. 2015:35(1):71-83. doi:10.1007/s10571-014-0101-6.

12. McGeer PL, McGeer EG. Targeting microglia for the treatment of Alzheimer's disease. Expert Opin Ther Targets. 2014;0(0):1-10. doi:10.1517/14728222. 2014.988707.

13. Rodhe J. Cell culturing of human and murine microglia cell lines. In: Joseph B, Venero JL, editors. Microglia. Methods Mol Biol: Humana Press; 2013. p. 11-6.

14. Stansley B, Post J, Hensley K. A comparative review of cell culture systems for the study of microglial biology in Alzheimer's disease. J Neuroinflammation. 2012;9(1):115.

15. Blasi E, Barluzzi R, Bocchini V, Mazzolla R, Bistoni F. Immortalization of murine microglial cells by a v-raf/v-myc carrying retrovirus. J Neuroimmunol. 1990;27(2-3):229-37. http://dx.doi.org/10.1016/01655728(90)90073-V.

16. Ginhoux F, Greter M, Leboeuf M, Nandi S, See P, Gokhan S, et al. Fate mapping analysis reveals that adult microglia derive from primitive macrophages. Science. 2010;330(6005):841-5. doi:10.1126/science.1194637.

17. Sedgwick JD, Schwender S, Imrich H, Dörries R, Butcher GW, ter Meulen V. Isolation and direct characterization of resident microglial cells from the normal and inflamed central nervous system. Proc Natl Acad Sci U S A. 1991;88(16):7438-42. doi:10.1073/pnas.88.16.7438.

18. De Haas AH, Boddeke HWGM, Brouwer N, Biber K. Optimized isolation enables ex vivo analysis of microglia from various central nervous system regions. Glia. 2007:55(13):1374-84. doi:10.1002/glia.20554.

19. Lee J, Tansey M. Microglia isolation from adult mouse brain. In: Joseph B, Venero JL, editors. Microglia. Methods Mol Biol: Humana Press; 2013. p. 17-23.

20. Blasi E, Mathieson BJ, Varesio L, Cleveland JL, Borchert PA, Rapp UR. Selective immortalization of murine macrophages from fresh bone marrow by a raf/myc recombinant murine retrovirus. Nature. 1985;318(6047):667-70.

21. Takanaga H, Yoshitake T, Hara S, Yamasaki C, Kunimoto M. CAMP-induced astrocytic differentiation of C6 glioma cells is mediated by autocrine interleukin-6. J Biol Chem. 2004:279(15):15441-7.

22. Woodling NS, Wang Q, Priyam PG, Larkin P, Shi J, Johansson JU, et al. Suppression of Alzheimer-associated inflammation by microglial prostaglandin-E2 EP4 receptor signaling. J Neurosci. 2014;34(17):5882-94. doi:10.1523/jneurosci.0410-14.2014.

23. Yang T, Knowles JK, Lu Q, Zhang H, Arancio O, Moore LA, et al. Small molecule, non-peptide p75 NTR ligands inhibit Aß-induced neurodegeneration and synaptic impairment. PLoS One. 2008;3(11):e3604. doi:10.1371/journal.pone.0003604. 
24. Kreutzberg GW. Microglia: a sensor for pathological events in the CNS Trends Neurosci. 1996;19(8):312-8. http://dx.doi.org/10.1016/01662236(96)10049-7.

25. Alliot F, Godin I, Pessac B. Microglia derive from progenitors, originating from the yolk sac, and which proliferate in the brain. Brain Res Dev Brain Res. 1999;117(2):145-52. http://dx.doi.org/10.1016/S0165-3806(99)00113-3.

26. Butovsky O, Jedrychowski MP, Moore CS, Cialic R, Lanser AJ, Gabriely G, et al. Identification of a unique TGF-[beta]-dependent molecular and functional signature in microglia. Nat Neurosci. 2014;17(1):131-43. doi:10. 1038/nn.3599. http://www.nature.com/neuro/journal/v17/n1/abs/nn.3599. html\#supplementary-information.

27. Sanz JM, Virgilio FD. Kinetics and mechanism of ATP-dependent IL-1 $\beta$ release from microglial cells. J Immunol. 2000;164(9):4893-8. doi:10.4049/ jimmunol.164.9.4893.

28. Hsu H-Y, Wen M-H. Lipopolysaccharide-mediated reactive oxygen species and signal transduction in the regulation of interleukin-1 gene expression. J Biol Chem. 2002;277(25):22131-9.

29. Zhou X, Spittau B, Krieglstein K. TGFbeta signalling plays an important role in IL4-induced alternative activation of microglia. J Neuroinflammation. 2012;9(1):210

30. Kim E-A, Han AR, Choi J, Ahn J-Y, Choi SY, Cho S-W. Anti-inflammatory mechanisms of $\mathrm{N}$-adamantyl-4-methylthiazol-2-amine in lipopolysaccharidestimulated BV-2 microglial cells. Int Immunopharmacol. 2014;22(1):73-83. http://dx.doi.org/10.1016/j.intimp.2014.06.022.

31. Horvath RJ, Nutile-McMenemy N, Alkaitis MS, DeLeo JA. Differential migration, LPS-induced cytokine, chemokine, and NO expression in immortalized BV-2 and HAPI cell lines and primary microglial cultures. J Neurochem. 2008;107(2):557-69. doi:10.1111/j.1471-4159.2008.05633.x.

32. Neniskyte U, Vilalta A, Brown GC. Tumour necrosis factor alpha-induced neuronal loss is mediated by microglial phagocytosis. FEBS Lett. 2014; 588(17):2952-6. doi:10.1016/j.febslet.2014.05.046.

33. Martin-Moreno AM, Brera B, Spuch C, Carro E, Garcia-Garcia L, Delgado M, et al. Prolonged oral cannabinoid administration prevents neuroinflammation, lowers B-amyloid levels and improves cognitive performance in Tg APP 2576 mice. J Neuroinflammation. 2012;9:8. doi:10.1186/1742-2094-9-8.

34. Martín-Moreno AM, Reigada D, Ramírez BG, Mechoulam R, Innamorato N, Cuadrado A, et al. Cannabidiol and other cannabinoids reduce microglial activation in vitro and in vivo: relevance to Alzheimer's disease. Mol Pharmacol. 2011;79(6):964-73. doi:10.1124/mol.111.071290.

35. Ramírez BG, Blázquez C, del Pulgar TG, Guzmán M, de Ceballos ML. Prevention of Alzheimer's disease pathology by cannabinoids: neuroprotection mediated by blockade of microglial activation. J Neurosci. 2005;25(8):1904-13. doi:10.1523/jneurosci.4540-04.2005.

36. Boche D, Perry VH, Nicoll JAR. Review: activation patterns of microglia and their identification in the human brain. Neuropathol Appl Neurobiol. 2013; 39(1):3-18. doi:10.1111/nan.12011.

37. Maccioni RB, Morales I, Guzman-Martinez L, Cerda-Troncoso C, Farías GA. Neuroinflammation in the pathogenesis of Alzheimer's disease. A rational framework for the search of novel therapeutic approaches. Front Cell Neurosci. 2014;8. doi:10.3389/fncel.2014.00112.

38. Koenigsknecht-Talboo J, Landreth GE. Microglial phagocytosis induced by fibrillar $\beta$-amyloid and IgGs are differentially regulated by proinflammatory cytokines. J Neurosci. 2005;25(36):8240-9. doi:10.1523/jneurosci.1808-05.2005.

39. Takata K, Kitamura Y, Yanagisawa D, Morikawa S, Morita M, Inubushi T, et al. Microglial transplantation increases amyloid- $\beta$ clearance in Alzheimer model rats. FEBS Lett. 2007;581(3):475-8. http://dx.doi.org/10.1016/j.febslet.2007.01.009.

40. Maezawa I, Zimin PI, Wulff H, Jin L-W. Amyloid- $\beta$ protein oligomer at low nanomolar concentrations activates microglia and induces microglial neurotoxicity. J Biol Chem. 2011;286(5):3693-706. doi:10.1074/jbc.M110.135244.

41. Hickman SE, Allison EK, El Khoury J. Microglial dysfunction and defective $\beta$ amyloid clearance pathways in aging Alzheimer's disease mice. J Neurosci. 2008;28(33):8354-60. doi:10.1523/jneurosci.0616-08.2008.

42. Fakhfouri G, Ahmadiani A, Rahimian R, Grolla AA, Moradi F, Haeri A. WIN55212-2 attenuates amyloid-beta-induced neuroinflammation in rats through activation of cannabinoid receptors and PPAR- $\gamma$ pathway. Neuropharmacology. 2012;63(4):653-66. http://dx.doi.org/10.1016/j. neuropharm.2012.05.013

\section{Submit your next manuscript to BioMed Central and we will help you at every step:}

- We accept pre-submission inquiries

- Our selector tool helps you to find the most relevant journal

- We provide round the clock customer support

- Convenient online submission

- Thorough peer review

- Inclusion in PubMed and all major indexing services

- Maximum visibility for your research

Submit your manuscript at www.biomedcentral.com/submit
Biomed Central 